\title{
SURFACE QUALITY OF THE MATERIALS USED FOR LIGHTING COLUMNS
}

doi: 10.2478/cqpi-2019-0057

Date of submission of the article to the Editor: 01/04/2019

Date of acceptance of the article by the Editor: 29/05/2019

\author{
Agata Dudek ${ }^{1}$ - orcid id: 0000-0001-9115-028X \\ Andrii Goroshko² - orcid id: 0000-0002-1386-2326 \\ ${ }^{1}$ Institute of Material Engineering, Faculty of Processing Engineering and Materials Technology, \\ Czestochowa University of Technology, Armii Krajowej 19, 42-200 Czestochowa, Poland \\ ${ }^{2}$ Khmelnytsky National University, Instytutska 11, 29016 Khmelnitsky, Ukraine
}

Abstract: Quality of the lighting columns plays a major role in the comfort and safety of life of road users. The surface quality of the materials used in the columns is especially critical during extreme weather conditions. Road infrastructure, including street lighting, uses modern lightweight materials from the group of non-ferrous materials or composites. The materials used in the manufacturing process ensure important advantages, such as durability, electrical safety, aesthetic qualities, low maintenance costs, light weight, and easy transport and assemble. This paper presents an analysis of the quality of coatings used for street lighting columns.

Keywords: lighting columns, coatings, quality

\section{INTRODUCTION}

The history of street lamps dates back to ancient Greece and Rome, and for hundreds of years, street lamps have constantly been evolving. The first street lanterns were wooden oil poles, which were replaced by oil lanterns in the middle of the 19th century. With William Murdoch's invention, gas lighting began to illuminate the streets of London and Paris. The progress in electrification has resulted in street lighting being almost entirely replaced by electric lamps (arc, incandescent, fluorescent, mercury, sodium and LED).

Roads and traffic routes are nowadays one of the most essential areas of the light source application, whereas lighting infrastructure is an important element of every city's architecture.

The main objective of the proper choice of lighting infrastructure (e.g. light sources, luminaires or lighting columns) is to provide road users with:

- driving safety,

- pedestrian traffic,

- public safety, 
- vision comfort,

- smooth traffic flow,

- electricity efficiency.

All of these factors are directly related to the proper choice and design of street lighting. In fulfilling the obligations resulting from the membership in the European Union, Poland had to implement several legal regulations and take measures to increase the energy efficiency of generation, transmission and end-user processes. Therefore, the European Committee for Standardization drafted the EN13201 standard, which became obligatory for "Road Lighting" and consists of four parts (Table 1).

Table 1

List of parts of the PN/EN 13201:2016 standard

\begin{tabular}{|l|l|}
\hline Number of standard & \multicolumn{1}{c|}{ Title: } \\
\hline PKN-CEN/TR 13201-1 & Part 1: Guidelines on selection of lighting classes. \\
\hline PN-EN 13201-2 & Part 2: Performance requirements. \\
\hline PN-EN 13201-3 & Part 3: Calculation of performance. \\
\hline PN-EN 13201-4 & Part 4: Methods of measuring lighting performance. \\
\hline
\end{tabular}

The first three parts of the standard are taken into consideration at the stage of design of street lighting. Apart from lighting parameters, the standards emphasize other important aspects, such as environmental aspects, aesthetics and appearance of the installation (columns, masts and luminaires) (PN-75/E-05100).

A lighting column is a support structure embedded directly in the ground or on a foundation, used to mount a luminaire at a height not greater than $14 \mathrm{~m}$ (PN-EN 401:2002). A lighting mast is a support structure embedded in the ground by means of a foundation, used to mount luminaires at a height equal to or greater than $14 \mathrm{~m}$. Furthermore, support structures for street lights (lighting columns or masts) are designed to support one or more luminaires and consist of one or more parts: a column, an extension component, and a jib. Until recently, the streets of most cities were dominated by concrete and steel columns. Current trends are focused on aluminium and composite columns.

Depending on the shape, steel street columns and masts can be divided into:

- straight hexagonal,

- straight octagonal,

- straight cylindrical,

- straight pipes,

- hexagonal with jibs,

- cylindrical with jibs,

- pipe-shaped with jibs,

- octagonal with jibs.

The columns made of aluminium can be divided into:

- straight pipe,

- straight conical,

- conical with jibs,

- pipe-shaped with jibs. 
When designing structures such as masts, columns, foundations and booms, two types of actions on the structure must be considered:

- constant - depending on the mass of the structure and the luminaire at the top of the column,

- variable - resulting from the effect of atmospheric conditions: wind, according to PN77/B-02011, PN-EN 1991-1-4 and snow, according to PN-EN 1991-1-3.

The support structures should also meet the requirements of the PN-EN 12767 standard concerning passive safety of road structures with reference to three defined speed levels at the moment of collision, i.e. 50,70 and $100 \mathrm{~km} / \mathrm{h}$. The standard classifies three levels of energy absorption by support structures:

- high energy absorbing (HE);

- low energy absorbing (LE);

- non energy absorbing (NE).

Furthermore, all components should be protected with an additional coating for corrosion protection. Such coatings vary depending on the material of which the road lighting support structures used to mount luminaires are made. Steel columns, masts and jibs are hot-dip galvanized on the outside and inside (with thickness depending on the thickness of steel) and can also be covered with a protective paint coating. Columns made of aluminium should be protected against corrosion by anodising, whereas the coating obtained should be at least $20 \mu \mathrm{m}$.

Steel columns and masts are mainly made of:

- steel strip or sheet metal, bent to a section with a polygonal or circular cross-section with a constant taper,

- pipes - seamless, graded tapered pipe columns.

The technologies of tube extrusion or rolling pipes are used for manufacturing steel columns (non-alloy structural steel), which eliminates the need for crosswise and longitudinal welding. In the case of steel sheets, their forming is performed, followed by joining by means of e.g. laser welding (PN-EN 40-5:2004).

Aluminium columns are made mainly of AIMg3 and AIMgSi alloys, depending on the strength properties required for various diameters and wall thickness from $3 \mathrm{~mm}$ to $10 \mathrm{~mm}$. As a result of the use of the technology of tube extrusion and rolling, a uniform structure is obtained without the need for welding (PN-EN 40-6:2004).

The main advantages of using steel or aluminium lighting columns and masts are as follows:

- resistance to corrosion: hot-dip galvanizing of steel columns and anodizing of aluminium columns (long service life);

- high dynamic and mechanical strength - the column structure provides good strength and vibration damping, which reduces the failure rate of luminaires and light sources;

- flexibility - the consequences of a collision between vehicles and the column are less severe than a collision with a concrete column;

- low weight - easy transport, easy and safer installation;

- modern shapes - a wide range of applications;

- possibility of coating with paint coatings;

- savings on running costs; 
- after use, possible transformation into an initial material.

The latest material proposal that has appeared in the market are columns made of composite materials. These are mainly columns made of polymer composites reinforced with glass fibre with round, conical or square shapes (PN-EN 40-7:2004). The advantages of lighting columns made of composite materials include:

- low weight;

- seamless design;

- no maintenance requirements

- dimensional stability

- resistance to temperature and UV radiation

- dielectric properties

- resistance to chemical and atmospheric agents

- low coefficient of linear thermal expansion

- low running costs,

- possibility of colouring

- smooth surface, aesthetic appearance and easy dirt removal

- $100 \%$ recyclable

- high vibration damping.

- possibility of printing texts or high-resolution photos on the column

- possibility to illuminate the column from the inside with an independent light source.

In recent years, composite columns with reflective coatings containing glass micro balls and LED tapes have also appeared on the market.

When considering the most important requirements and properties of individual lighting columns or masts, special attention should be paid to the role of the external surface (surface layers) which is in direct contact with the environment.

The high performance of lighting columns or masts can only be ensured if the highquality layers are applied on their surface, which is, therefore, a key problem of the present paper.

\section{RESULTS}

The practical part presents structural examinations of the most commonly used coatings for support structures of road lighting, mainly with regard to their quality. The samples of columns and masts used for street lighting were collected for the study. Two types of columns were selected: anodised aluminium columns and galvanized steel columns.

The analysis with the use of optical and scanning microscope was performed in terms of key parameters such as: adhesion of coatings to the core material, thickness, and structure of the coatings used.

The coatings shown in Fig. 1 and Fig. 2 revealed on the examined aluminium columns were made by controlled electrolytic oxidation of the surface, resulting in obtaining a protective layer of aluminium oxide. 


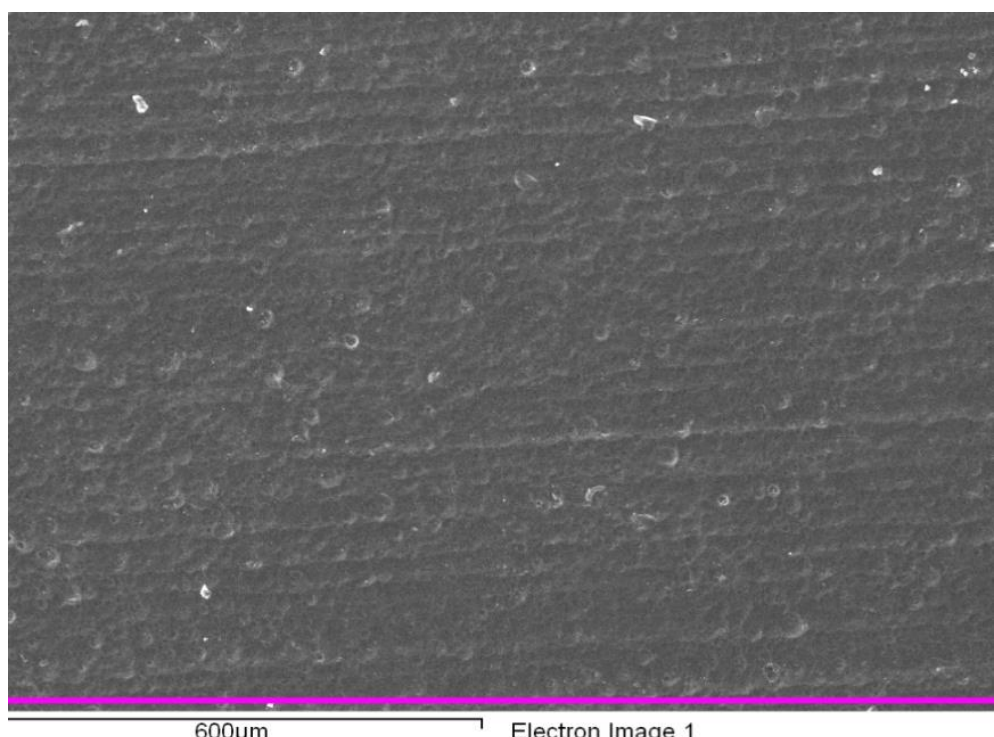

Fig.1. Appearance and structure of the anodized coating on the surface of the aluminium column
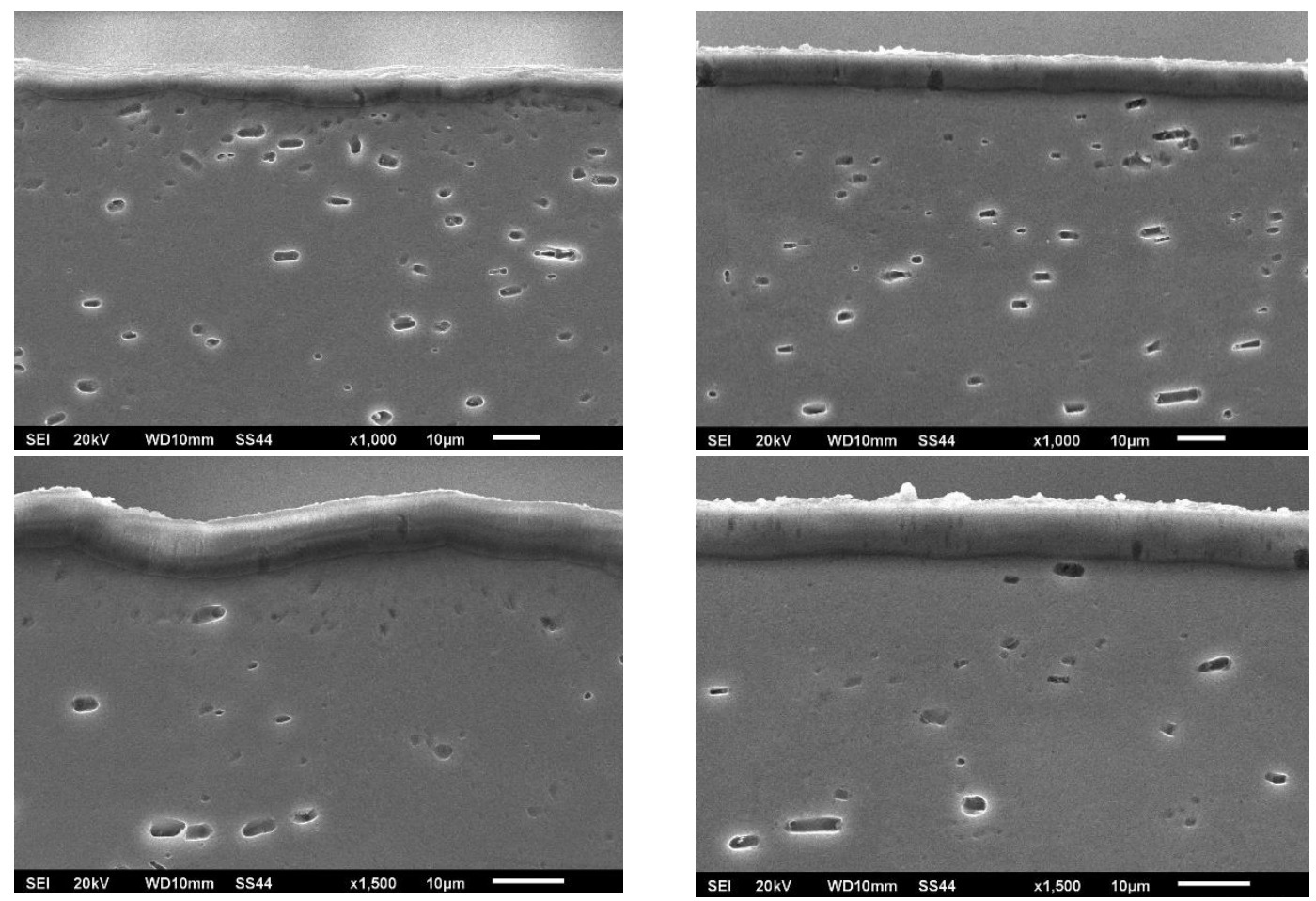

Fig. 2. Cross-section of an anodised aluminium column

The thickness of the anode coating was approximately $20 \mu \mathrm{m}$, ensuring safe application in moderate to severe conditions. The coating was characterized by a compact, uniform structure along the entire length and had very good adhesion to the aluminium alloy core material. No cracks, delaminations or cavities were found in the coating. 


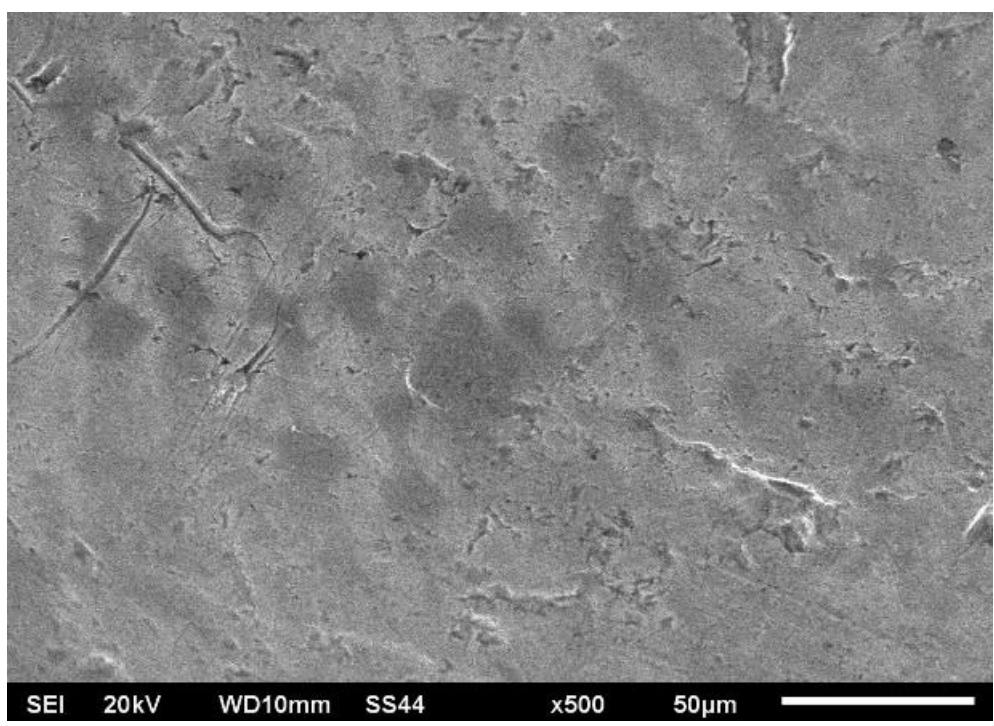

Fig. 3. Appearance and structure of the hot-dip galvanized coating on structural steel
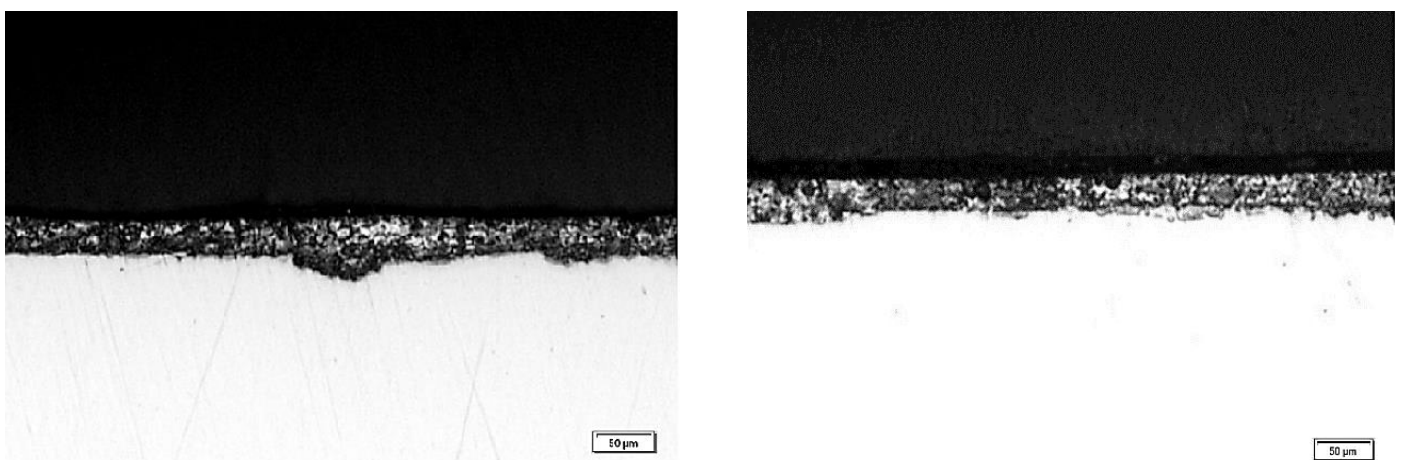

Fig. 4. Cross-section of a steel column with galvanized coating

The coatings on steel columns obtained by hot-dip galvanizing (Fig.3 and Fig.4) had thickness of approximately $45 \mu \mathrm{m}$. They were characterized by a compact, uniform structure with a smooth surface and excellent adhesion to the steel core material. No cracks or delaminations were found.

\section{CONCLUSION}

The long-term protection of lighting infrastructure by using protective layers on the surfaces of the components used continues to be a challenge for material engineers and designers. Proper choice of the type of a protective coating to the surrounding conditions and requirements allows to adequately protect the structures, improving their quality and durability over many years. Material tests of the quality of applied example coatings on lighting columns (steel and aluminium alloy) confirmed the high quality of technologies used to produce protective coatings.

Similar long-term protection coatings may be very useful in wide variety of other protective applications in aggressive environments e.g. biotechnological apparatus (Skrzypczak-Pietraszek and Pietraszek, 2009; Skrzypczak-Pietraszek et al., 2018), heavy-duty machines (Ferdek and Kozien, 2013; Augustyn and Kozien, 2014; FabisDomagala et al., 2018). The obtained results may be very inspiring for other researcher focused on surface layer (Bara et al., 2009; Korzekwa et al., 2018; Radek et al., 2014; 
Radek et al., 2018; Skoneczny et al., 2018), corrosion resistance (Szabracki and Lipinski, 2013; Lipinski and Wach, 2014) and - associated with them - practical image analysis methods (Gadek-Moszczak and Wojnar, 2009; Gadek-Moszczak et al., 2014; Wojnar et al., 2019). It may also influence uncertainty quantifications methods (Kozien and Kozien, 2017; Pietraszek et a., 2017a; Pietraszek et al., 2017b; Pietraszek et al., 2018), recently very popular due to usability of surrogate models and associated with the uncontrolled factors of the natural environment.

\section{REFERENCES}

Augustyn, E., Kozien, M.S., 2014. A Study on Possibility to Apply Piezoelectric Actuators for Active Reduction of Torsional Beams Vibrations. Acta Physica Polonica A, 125, A164-A168.

Bara, M., Skoneczny, W., Hajduga, M., 2009. Ceramic-graphite surface layers obtained by the duplex method on an aluminium alloy substrate. Chemical and Process Engineering, 30, 431-442.

Fabis-Domagala, J., Filo, G., Momeni, H., Domagala, M., 2018. Instruments of identification of hydraulic components potential failures. MATEC Web Conf., 183, art. 03008. DOI: 10.1051/matecconf/201818303008

Ferdek, U.; Kozien, M. S. 2013. Simulation of Application of FGM Piezoelectric Actuators for Active Reduction of Beam Vibrations. Acta Physica Polonica A, 123, 1044-1047. DOI: 10.12693/APhysPolA.123.1044

Gadek-Moszczak, A., Radek, N., Wronski, S., Tarasiuk, J., 2014. Application the 3D image analysis techniques for assessment the quality of material surface layer before and after laser treatment. Adv. Mat. Res. Switz., 874, 133-138. DOI: 10.4028/www.scientific.net/AMR.874.133

Gadek-Moszczak, A., Wojnar, L. 2009. Objective, quantitative and automatic $x$-ray image analysis of the bone regenerate in the ilizarov method. ECS10: The $10^{\text {th }}$ European Congress of Stereology and Image Analysis, Milan, Int. Society for Stereology, 453-458.

Korzekwa, J., Gadek-Moszczak, A., Zubko, M., 2018. Influence of the size of nanoparticles on the microstructure of oxide coatings. Materials Science, 53, 709716. DOI: 10.1007/s11003-018-0127-x

Kozien, E., Kozien, M.S., 2017. Interval analysis as a method of measurement of uncertainity in the check-list method applied to identification of stage phase of companies. $26^{\text {th }}$ Int. Sci. Conf. Economic and Social Development - Building Resilient Society, Zagreb, Croatia, Varazdin, 210-215.

Lipinski, T., Wach, A., 2014. Influence of outside furnace treatment on purity medium carbon steel. Metal 2014: $23^{\text {rd }}$ Int. Conf. Metallurgy And Materials, Ostrava, Tanger, 738-743.

Pietraszek, J., Dwornicka, R., Krawczyk, M., Kołomycki, M., 2017a. The non-parametric approach to the quantification of the uncertainty in the design of experiments modelling. UNCECOMP 2017: $2^{\text {nd }}$ Int. Conf. Uncertainty Quantification in Computational Sciences and Engineering, Rhodes, NTU of Athens, 598-604. DOI: 10.7712/120217.5395.17225

Pietraszek, J., Szczotok, A., Kolomycki, M., Radek, N., Kozien, E., 2017b. Nonparametric assessment of the uncertainty in the analysis of the airfoil blade traces. METAL 2017: 26 ${ }^{\text {th }}$ Int. Conf. Metallurgy and Materials. Ostrava, Tanger, 1412-1418. 
Pietraszek, J., Radek, N., Scendo, M., Staszewska-Samson, K., Osocha, P., 2018. Estimation of the quantitative uncertainty for the corrosion potential and corrosion current density. METAL 2018: $27^{\text {th }}$ Int. Conf. Metallurgy and Materials. Ostrava, Tanger, 1204-1209.

PN-EN 13201:2016 - Road lighting

PN-75/E-05100 Overhead power lines. Design and construction

PN-EN 40-1:2002 Lighting columns. Terms and definitions

PN-EN 1991-1-4 Actions on structures - Part 1-4: General actions - Wind actions

PN-EN 1991-1-3 General actions - Snow load

PN-EN 12767:2008: Passive safety of support structures for road equipment. Requirements, classification and test methods.

PN-EN 40-5:2004 Lighting columns. Part 5: Requirements for steel lighting columns.

PN-EN 40-6:2004 Lighting columns. Part 6: Requirements for aluminium lighting columns.

PN-EN 40-7:2004 Lighting columns. Part 7: Requirements for fibre reinforced polymer composite lighting columns.

Radek, N., Pietraszek, J., Antoszewski, B., 2014. The Average Friction Coefficient of Laser Textured Surfaces of Silicon Carbide Identified by RSM Methodology. Adv. Mat. Res.-Switz., 874, 29-34. DOI: 10.4028/www.scientific.net/AMR.874.29

Radek, N., Szczotok, A., Gadek-Moszczak, A., Dwornicka, R., Broncek, J., Pietraszek, J., 2018. The impact of laser processing parameters on the properties of electrospark deposited coatings. Arch. Metall. Mater., 63, 809-816. DOI: 10.24425/122407

Skoneczny, W., Niedzwiedz, M., Bara, M., 2018. The effect of production parameters of oxide layers on their nanostructure, nanomorphology and surface free energy. Applied Sciences-Basel, 8, art. 2251. DOI: 10.3390/app8112251

Skrzypczak-Pietraszek, E., Pietraszek, J., 2009. Phenolic acids in in vitro cultures of Exacum affine Balf. f. Acta Biol. Cracov. Bot., 51, 62-62.

Skrzypczak-Pietraszek E., Piska, K., Pietraszek, J., 2018. Enhanced production of the pharmaceutically important polyphenolic compounds in Vitex agnus castus L. shoot cultures by precursor feeding strategy. Enginnering in Life Sciences, 18, 287-297.

Szabracki, P., Lipinski, T., 2013. Effect of Aging on the Microstructure and the Intergranular Corrosion Resistance of X2CrNiMoN25-7-4 Duplex Stainless Steel. Solid State Phenomena, 203-204, 59-62. DOI: 10.4028/www.scientific.net/SSP.203204.59

Wojnar, L., Gadek-Moszczak A., Pietraszek J., 2019. On the role of histomorphometric (stereological) microstructure parameters in the prediction of vertebrae compression strength. Image Analysis and Stereology, 38, 63-73. DOI: 10.5566/ias.2028 